\title{
PENGARUH KUALITAS PRODUK DAN CITRA MEREK TERHADAP KEPUTUSAN PEMBELIAN KOSMETIK WARDAH PT PARAGON TEHNOLOGY AND INNOVATION
}

\author{
Rosa Lesmana*) \\ email : rosa.sunardi@gmail.com \\ Suci Dara $\mathrm{Ayu}^{\star \star}$ )
}

ABSTRAK

Tujuan dari penelitian ini untuk mengetahui pengaruh Kualitas Produk dan Citra Merek terhadap keputusan pembelian kosmetik Wardah pada PT. Paragon Technology and Innovation secara simultan.

Populasi dalam enelitian adalah konsumen yang telah menggunakan kosmetik Wardah, dengan responden sebanyak 100 orang. Data dianalisis menggunakan uji statistik assosiatif deskriptif, uji validitas, uji reliabilitas, uji asumsi klasik, uji regresi linier berganda, uji korelasi, koefisien determinasi, uji t dan uji f.

Hasil penelitian menunjukkan bahwa Kualitas Produk dan Citra Merek berpengaruh positif dan signifikan secara simultan terhadap Keputusan Pembelian Kosmetik Wardah. Dengan persamaan regresi $Y=1.340+0,275 X 1+0,721 X 2$, dan hasil uji korelasi sebesar $X 1=$ 0,832 , $X 2=0,869$, koefisien determinasi ( $R$ square sebesar $88.3 \%$, hasil uji $F$ dapat diperoleh nilai $f$ hitung $>$ f tabel yaitu $170.897>3,09$ dan nilai sig $<0,05$ atau $0,000<0,05$.

Kata Kunci : Kualitas Produk, Citra Merek, dan Keputusan Pembelian

\section{ABSTRACT}

This study aims to examine the factors which influencing the demand of soybean in Indonesia. The basic method used in this study is descriptive analysis with secondary data which includes the prices of local soybean, the prices of imported soybean, the prices of chicken meat, income per capita, inflation rate, and the imposition of import tariff in year period 1980 to 2013 sourced from Badan Pusat Statistik (BPS) and other sources. Estimation of demand function using multiple linear regression analysis were transformed into logarithm.

The result of regression anlysis showed that simultaneously independent variables significantly influence the dependent variable with $R^{2}$ value is $65,1 \%$. Partially, the prices of chicken meat, income per capita, and inflation rate has significantly influence on demand of soybean. While the prices of local soybean,the prices of imported soybean and import tariff has no significantly influence on demand of soybean.

Keywords: demand analysis, elasticity, soybean

\section{A. Pendahuluan}

Wardah adalah salah satu kosmetik yang mengusung kosmetik "halal". Wardah percaya bahwa citra positif, bisa meningkatkan kepercayaan diri wanita Indonesia untuk berkarya. Dengan perawatan dan kosmetik yang tepat, mereka bisa mendapatkan penampilan, karir, dan kehidupan yang lebih baik. Seluruh rangkaian wardah kosmetik dibuat dari bahan berkualitas dan terbukti aman serta halal. Wardah diformulasikan oleh para ahli farmasi dan kecantikan yang menghadirkan produk dengan inovasi terkini . seluruhnya didedikasikan untuk wanita modern agar semakin percaya diri melalui produk yang berkualitas. Wardah terbuat dari bahan-bahan 
berkualitas yang aman dan telah mendapat SJH (Sertifikat Jaminan Halal) dari LPPOM MUI serta seluruh produknya telah mendapat izin dan memenuhi peraturan BP POM RI.

Kualitas produk merupakan hal yang penting yang harus diusahakan oleh perusahaan. Hasil penelitian Habibah dan sumiati, (2016) dalam penelitian ini menyatakan bahwa variabel independen (Kualitas Produk) pemiliki pengaruh paling dominan terhadap varibel dependen (Keputusan Pembelian) karena produk yang berkualitas tinggi adalah produk yang merangsang persepsi dan emosional konsumen yang berdampak pada keputusan pembeliam melalui variasi, warna dan desain.

Berikut data kosmetik dengan citra halal di Indonesia

Tabel 1.1

Daftar kosmetik Halal

\begin{tabular}{|c|c|c|c|}
\hline No & $\begin{array}{c}\text { Daftar Kosmetik } \\
\text { Halal }\end{array}$ & No & $\begin{array}{c}\text { Daftar Kosmetik } \\
\text { Halal }\end{array}$ \\
\hline 1 & Wardah & 8 & PAC \\
\hline 2 & Ristra & 9 & Mustika Ratu \\
\hline 3 & La Tulipe & 10 & Moors \\
\hline 4 & Marcks Venus & 11 & Mustika Puteri \\
\hline 5 & Sari Ayu & 12 & Biocell \\
\hline 6 & Biokos & 13 & Rivera \\
\hline 7 & Caring Colours & 14 & Theraskin \\
\hline
\end{tabular}

Sumber : e-Ippommui.org

Tabel 1.2

Data Penjualan Kosmetik di beberapa Mall di Tangerang bulan Oktober-Desember 2018

\begin{tabular}{|c|l|c|c|c|}
\hline $\begin{array}{c}\text { Nama } \\
\text { tempat/Mall }\end{array}$ & Brand & $\begin{array}{c}\text { Pendapatan } \\
\text { Oktober }\end{array}$ & $\begin{array}{c}\text { Pendpatan } \\
\text { November }\end{array}$ & $\begin{array}{c}\text { Pendapatan } \\
\text { Desember }\end{array}$ \\
\hline \multirow{2}{*}{$\begin{array}{c}\text { Tangerang } \\
\text { City }\end{array}$} & Revlon & 95.732 .200 & 96.603 .400 & 97.232 .540 \\
\cline { 2 - 5 } & Maybelin & 71.355 .100 & 72.283 .500 & 71.310 .500 \\
\cline { 2 - 5 } & L'oreal & 51.117 .200 & 50.498 .490 & 52.203 .000 \\
\hline
\end{tabular}




\begin{tabular}{|c|c|c|c|c|}
\hline & SilkyGrils & 31.411 .050 & 30.516 .500 & 32.125 .300 \\
\hline & Wardah & 37.295 .420 & 36.587 .500 & 29.727 .560 \\
\hline & Externally & 14.312 .500 & 15.302 .700 & 15.212 .500 \\
\hline & Latulipe & 8.532 .120 & 8.774 .200 & 7.425 .00 \\
\hline \multirow{7}{*}{$\begin{array}{c}\text { Lippo } \\
\text { Karawaci }\end{array}$} & Revlon & 87.352 .420 & 89.729 .000 & 92.312 .000 \\
\hline & Maybelin & 69.522 .700 & 70.420 .155 & 71.298 .700 \\
\hline & L'oreal & 48.980 .225 & 47.215 .700 & 49.351 .000 \\
\hline & SilkyGrils & 35.121 .500 & 33.420 .000 & 33.120 .000 \\
\hline & Wardah & 42.453 .000 & 41.729 .000 & 43.845 .100 \\
\hline & Externally & 12.411 .723 & 14.15 .200 & 3.557 .000 \\
\hline & Latulipe & 9.421 .320 & 8.530 .100 & 8.225 .300 \\
\hline \multirow{7}{*}{$\begin{array}{c}\text { Summarecon } \\
\text { Serpong }\end{array}$} & Revlon & 85.411 .700 & 84.502 .100 & 86.735 .500 \\
\hline & Maybelin & 68.537 .200 & 69.417 .520 & 70.543 .300 \\
\hline & L'oreal & 55.221 .400 & 54.137 .205 & 53.142 .500 \\
\hline & SilkyGrils & 30.425 .700 & 30.125 .550 & 31.225 .000 \\
\hline & Wardah & 45.572 .500 & 44.157 .200 & 46.856 .300 \\
\hline & Externally & 13.212 .400 & 14.157 .200 & 13.225 .600 \\
\hline & Latulipe & 10.754 .145 & 9.481 .200 & 7.766 .500 \\
\hline \multirow{7}{*}{ Metropolis } & Revlon & 77.297 .510 & 79.610 .550 & 80.792 .000 \\
\hline & Maybelin & 69.543 .125 & 67.796 .435 & 65.145 .000 \\
\hline & L'oreal & 49.795 .200 & 47.986 .213 & 47.195 .700 \\
\hline & SilkyGrils & 30.455 .132 & 30.402 .500 & 31.746 .500 \\
\hline & Wardah & 31.255 .400 & 29.696 .250 & 27.946 .000 \\
\hline & Externally & 13.525 .174 & 12.765 .200 & 11.952 .900 \\
\hline & Latulipe & 8.917 .200 & 8.657 .000 & 9.752 .000 \\
\hline
\end{tabular}

Sumber : diolah peneliti dari beberapa tempat/mall ditangerang

Berdasarkan tabeldiatas menunjukkan bahwa di beberapa mall penjualan kosmetik Revlon berada pada urutan pertama. Sedangkan kosmetik Wardah, memiliki penjualan yang tiak terlalu tinggi. Penjualan kosmetik Wardah cukup baik namun belum dapat menyaingi penjualan kosmetik Revlon.

Berdasarkan penjelasan diatas, maka penulis memilih judul "Pengaruh Kualitas Produk dan Citra Merek terhadap Keputusan Pembelian Kosmetik Wardah".

\section{B. Rumusan Masalah}


Bagaimana pengaruh kualitas produk dan citra merek pada keputusan pembelian kosmetik Wardah PT Paragon Technologi and Innovation?

\section{Tujuan Penelitian}

Untuk megetahui pengaruh kualitas produk dan citra merek pada keputusan pembelian kosmetik Wardah PT Paragon Technologi and Innovation?

\section{Landasan teori}

Kualitas Produk

Menurut Garvin dalam Sonny Santosa (2010:114) "kualitas adalah suatu kondisi dinamis yang berhubungan dengan produk, manusia atau tenaga kerja, proses dan tugas, serta lingkungan yang memenuhi atau melebihi harapan pelanggan".

Munurut Kotler \& Armstrong (2010, p248), Produk adalah segala sesuatu yang dapat ditawarkan kepada pasar agar menarik perhatian, akuisisi, penggunaan atau konsumsi yang dapat memuaskan suatu keinginan dan kebutuhan.

Citra Merk

Menurut Kotler dan Keller (2012:274), Citra Merek adalah cara masyarakat menganggap merek secara aktual. Atau persepsi masyarakat terhadap perusahaan atau produknya. Citra dipengaruhi oleh banyak faktor yang diluar kontrol perusahaan.

Keputusan Pembelian

Keputusan Pembelian menurut Kotler \& Keller (2016:198), "In the evaluation stage, the consumer forms preferences among the brands in the choice and may also form an intention to buy the most preferred brand". Sedangkan menurut Ujang Sumawan (2010 : 377), keputusan pembelian adalah : "Bagaimana konsumen memutuskan alternatif pilihan yang akan dipilih, serta meliputi keputusan mengenai apa yang dibeli, apakah membeli atau tidak, kapan membeli, dimana membeli, dan bagaimana cara membayarnya".

\section{E. Metode Penelitian}

Populasi dalam penelitian ini adalah konsumen yang datang dan terdaftar di PT Paragon Technology Innovation seluruh cabang dari triwulan 1 tahun 2016 sampai dengan triwulan 3 tahun 2018 sebanyak 82.866 konsumen. Sampel didapat dari rumus Slovin sebanyak 100 responden.

Pengujian Instrument 
Menggunakan uji Validitas. Uji realiabilitas, uji asumsi klasik.

Analisis Data

Menggunakan uji Regresi linear berganda, uji korelasi, koefisien determinasi dan uji hipotesis $\mathrm{T}$ dan $\mathrm{F}$

F. HASIL DAN PEMBAHASAN

Uji Validitas

Tabel 4.1

Rangkuman Hasil Uji Validitas Variabel Penelitian

\begin{tabular}{|c|c|c|c|}
\hline \multicolumn{4}{|c|}{ Kualitas Produk (X1) } \\
\hline No & \multirow{2}{*}{$\begin{array}{c}\text { Koefisien } \\
\text { Korelasi }\end{array}$} & \multirow{2}{*}{ R Tabel } & \multirow{2}{*}{ Keterangan } \\
\hline Kuisioner & & & \\
\hline 1 & 0.711 & 0.196 & Valid \\
\hline 2 & 0.783 & 0.196 & Valid \\
\hline 3 & 0.559 & 0.196 & Valid \\
\hline 4 & 0.806 & 0.196 & Valid \\
\hline 5 & 0.664 & 0.196 & Valid \\
\hline 6 & 0.859 & 0.196 & Valid \\
\hline 7 & 0.855 & 0.196 & Valid \\
\hline 8 & 0.776 & 0.196 & Valid \\
\hline 9 & 0.723 & 0.196 & Valid \\
\hline 10 & 0.313 & 0.196 & Valid \\
\hline \multicolumn{4}{|c|}{ Citra Merek (X2) } \\
\hline 1 & 0.339 & 0.196 & Valid \\
\hline 2 & 0.732 & 0.196 & Valid \\
\hline 3 & 0.555 & 0.196 & Valid \\
\hline 4 & 0.623 & 0.196 & Valid \\
\hline 5 & 0.646 & 0.196 & Valid \\
\hline 6 & 0.776 & 0.196 & Valid \\
\hline 7 & 0.318 & 0.196 & Valid \\
\hline 8 & 0.672 & 0.196 & Valid \\
\hline 9 & 0.466 & 0.196 & Valid \\
\hline 10 & 0.275 & 0.196 & Valid \\
\hline
\end{tabular}




\begin{tabular}{|c|c|c|c|}
1 & 0.644 & 0.196 & Valid \\
\hline 2 & 0.557 & 0.196 & Valid \\
\hline 3 & 0.626 & 0.196 & Valid \\
\hline 4 & 0.520 & 0.196 & Valid \\
\hline 5 & 0.785 & 0.196 & Valid \\
\hline 6 & 0.726 & 0.196 & Valid \\
\hline 7 & 0.844 & 0.196 & Valid \\
\hline 8 & 0.816 & 0.196 & Valid \\
\hline 9 & 0.360 & 0.196 & Valid \\
\hline 10 & 0.547 & 0.196 & Valid \\
\hline
\end{tabular}

Sumber : Data yang diolah SPSS 2019

Berdasarkan tabel 4.10 diatas maka dapat disimpulkan instrumen pada variabel Kualitas Produk X1, Citra Merek X2 dan keputusan pembelian Y dapat dikatakan valid, karena $r$ hitung dari masing-maasing butir pernyataan lebih besar dari nilai $r$ tabel yaitu 0,196

Uji Reabilitas

Tabel 4.2

Rangkuman Analisa Uji Reliabilitas

\begin{tabular}{|c|c|c|}
\hline Variabel & \multicolumn{2}{|c|}{ Reliability Statistics } \\
\hline & Cronbach's Alpha & N of Items \\
\hline $\mathrm{X} 1$ & 0,768 & 0.60 \\
\hline $\mathrm{X} 2$ & 0,713 & 0.60 \\
\hline $\mathrm{Y}$ & 0,759 & 0.60 \\
\hline
\end{tabular}

Sumber : Data primer yang diolah SPSS 2019

Dari hasil pergitungan variabel $\mathrm{X} 1, \mathrm{X} 2$ dan $\mathrm{Y}$ dengan menggunakan software SPSS, maka bisa dikatakan bahwa kuesioner reliabel dikarenakan nilai alpha cronbach $>0,60$.

Hasil Uji Asumsi Klasik

a. Uji Normalitas 


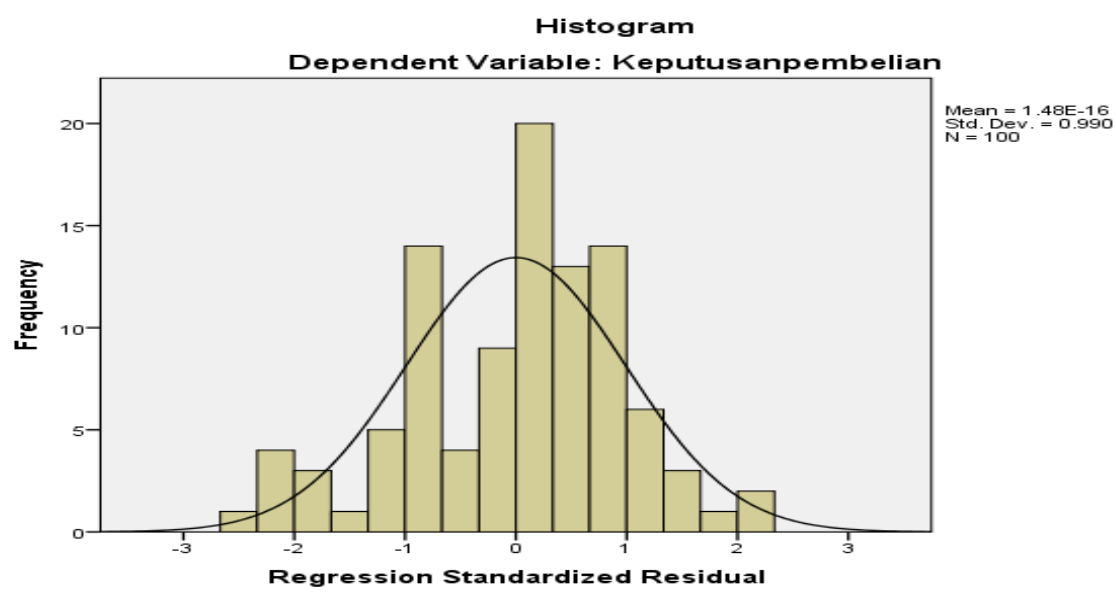

Sumber: Data yang diolah SPSS yang diolah (2019)

\section{Gambar 4.1}

\section{Histogram Keputusan Pembelian}

Berdasarkan grafik histogram di atas terlihat pola distribusi yang melenceng kekanan yang artinya data tersebut berdistribusi normal.

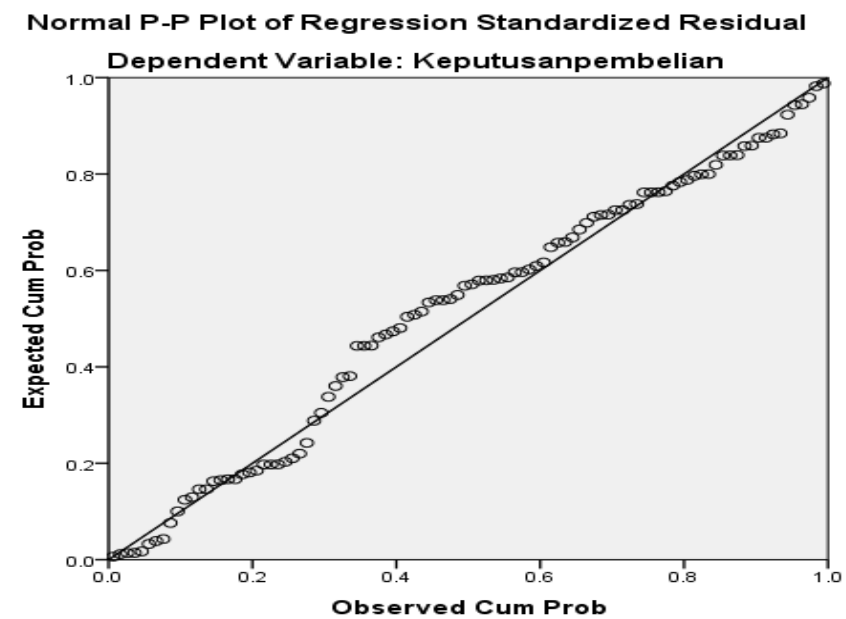

Sumber: Data yang diolah SPSS (2019)

Gambar 4.2

\section{P-P Plot of Regression standardized Residual keputusan pembelian}

Berdasarkan gambar 4.3 diatas terlihat titik-titik menyebar disekitar garis diagonal, ini menunjukan bahwa model regresi tidak menyalahi asumsi normalitas. 
b. Uji Multikolinieritas

Tabel 4.12

Hasil Data SPSS Uji Multikolinieritas

Coefficients $^{\mathrm{a}}$

\begin{tabular}{|c|c|c|c|c|c|c|c|}
\hline \multirow[b]{2}{*}{ Model } & \multicolumn{2}{|c|}{$\begin{array}{c}\text { Unstandardized } \\
\text { Coefficients }\end{array}$} & \multirow{2}{*}{$\begin{array}{c}\text { Standardized } \\
\text { Coefficients } \\
\text { Beta }\end{array}$} & \multirow[b]{2}{*}{$\mathrm{T}$} & \multirow[b]{2}{*}{ Sig. } & \multicolumn{2}{|c|}{$\begin{array}{l}\text { Collinearity } \\
\text { Statistics }\end{array}$} \\
\hline & B & Error & & & & Tolerance & VIF \\
\hline $1 \quad$ (Constant) & 1,340 & 1,569 & & 2,854 & ,003 & & \\
\hline $\begin{array}{l}\text { Kualitas } \\
\text { produk }\end{array}$ & ,275 & ,084 & ,316 & 3,274 & ,000 & ,245 & 4,087 \\
\hline $\begin{array}{l}\text { Citra } \\
\text { merek }\end{array}$ & ,721 & ,117 & ,594 & 6,154 & ,000 & ,245 & 4,087 \\
\hline
\end{tabular}

a. Dependent Variable: Keputusan pembelian

Sumber : Data yang diolah SPSS (2019)

Hasil uji multikolinieritas pada tabel 4.17 menunjukan nilai tolrance variabel Kualitas Produk ( X1) dan Citra Merek (X2) yakni 0,245 > 0,10, i VIF variabel Kualitas Produk (X1) dan Citra Merek (X2) yakni 4,087 dibawah lebih kecil dari 10. Menunjukan bahwa model regresi tidak model regresi tidak terdapat mutikolonieritas

\section{Uji Heteroskdastisitas}

Scatterplot

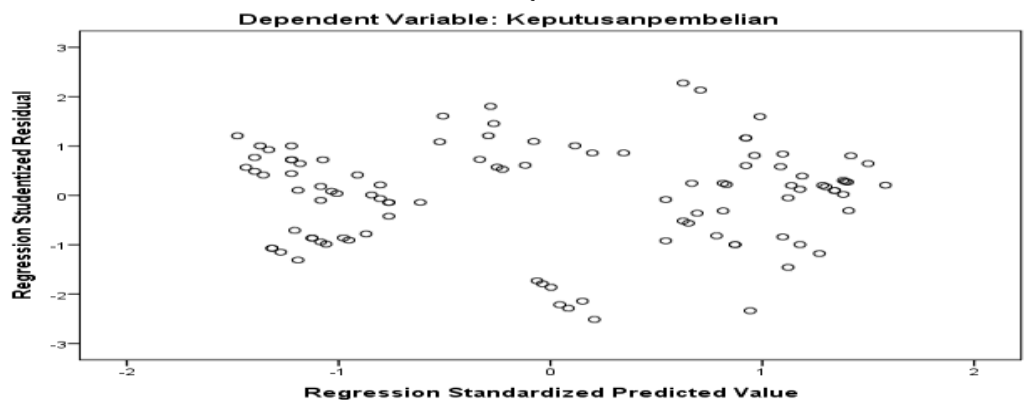

Sumber: Data yang diolah dari SPSS (2019)

Gambar 4.3

Grafik Scatterplot 


\section{Metode Analisa Data}

Uji Regresi Linier Berganda

Tabel 4.15

Hasil Uji Regresi Linear Berganda

\begin{tabular}{|c|r|r|r|r|r|}
\hline \multirow{2}{*}{ Model } & \multicolumn{2}{|c|}{$\begin{array}{c}\text { Unstandardized } \\
\text { Coefficients }\end{array}$} & $\begin{array}{c}\text { Standardized } \\
\text { Coefficients }\end{array}$ & & \\
\cline { 2 - 5 } & B & Std. Error & Beta & $\mathrm{t}$ & Sig. \\
\hline Kualitas produk & 1,340 & 1,569 & & 2,854 &, 003 \\
Citra merek &, 275 &, 084 &, 316 & 3,274 &, 000 \\
&, 721 &, 117 &, 594 & 6,154 &, 000 \\
\hline
\end{tabular}

a. Dependent Variable: Keputusan pembelian

Sumber : Data yang iolah SPSS (2019)

Dari tabel diatas didapat persamaan regresi berganda $\mathrm{X} 1=0,275$ dan $\mathrm{X} 2=$ 0,721 diperoleh model persamaan regresinya adalah $Y=1.340+0,275 X 1+0,721 X 2$, dimana artinya:

a. Nilai konstanta sebesar 1.340 diartikan bahwa jika variabel $X_{1}$ dan $X_{2}$ tidak ada maka telah terdapat keputusan pembelian sebesar 1.340.

b. Koefisien regresi $X_{1}$ sebesar 0,275 artinya jika nilai Kualitas Produk mengalami kenaikan sebesar 1 (satu) poin sementara Citra Merek diasumsikan tetap, maka akan menyebabkan kenaikan keputusan pembelian sebesar 0,275 point

c. Koefisien regresi $X_{2}$ sebesar 0,721 artinya jika nilai Kualitas Produk mengalami kenaikan sebesar 1 (satu) poin sementara Citra Merek diasumsikan tetap, maka akan menyebabkan kenaikan Keputusan pembelian sebesar 0,721 point

\section{Uji Korelasi}

\section{Tabel 4.20}

Hasil Uji Koefisien Korelasi X1,X2 terhadap Y, Secara Simultan

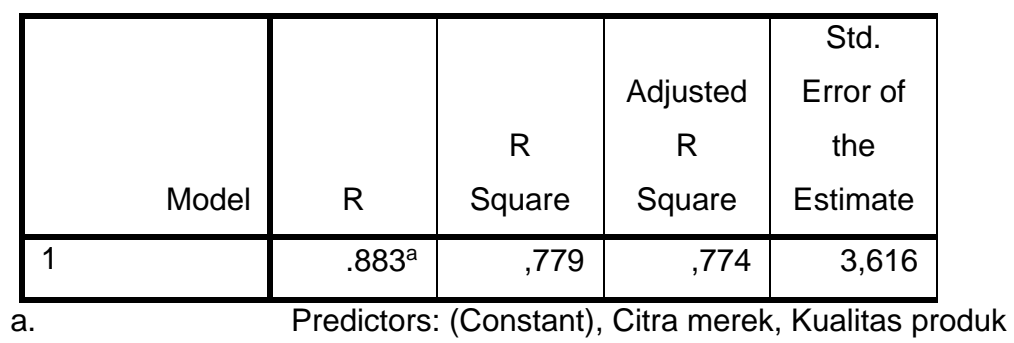

Sumber: Data SPSS yang diolah (2019) 
Berdasarkan nilai korelasi yang didapat maka diketahui bahwa, nilai koefisen korelasi dapat dilihat dengan nilai $R$ yaitu 0,883 dimana Kualitas Produk (X1) dan Citra Merek (X2) memiliki hubungan yang "sangat kuat" dan simultan terhadap keputusan pembelian $(\mathrm{Y})$ karena 0,883 berada diantara $0,80 \mathrm{~s} / \mathrm{d} 1000$

Uji Koefisien Determinasi $\left(\mathbf{R}^{2}\right)$

Tabel 4.23

Hasil Uji Koefisien Determinasi X1 dan X2 Terhadap Y

Model Summary

\begin{tabular}{|l|r|r|r|r|}
\hline Model & $\mathrm{R}$ & $\mathrm{R}$ Square & $\begin{array}{c}\text { Adjusted R } \\
\text { Square }\end{array}$ & $\begin{array}{c}\text { Std. Error of } \\
\text { the Estimate }\end{array}$ \\
\hline 1 & $.883^{\mathrm{a}}$ & .779 & .774 & 3.616 \\
\hline
\end{tabular}

a. Predictors: (Constant), Citra merek, Kualitas produk

b. Dependent Variable: KEPUTUSAN

Sumber: Data yang diolah SPSS (2019)

Koefisien Determinasi ( $R$ square) sebesar 0,779. berarti Kualitas produk (X1) dan Citra Merek (X2) berkontribusi terhadap kepeutusan pembelian (Y) sebesar $77.9 \%$

Pengujian Hipotesis.

Hasil Uji Parsial (Uji T) 
Tabel 4.25

Hasil Uji Parsial (Uji t)

Coefficients $^{\mathrm{a}}$

\begin{tabular}{|c|c|c|c|c|c|}
\hline \multirow[b]{2}{*}{ Model } & \multicolumn{2}{|c|}{$\begin{array}{l}\text { Unstandardized } \\
\text { Coefficients }\end{array}$} & \multirow{2}{*}{$\begin{array}{c}\text { Standardized } \\
\text { Coefficients } \\
\text { Beta }\end{array}$} & \multirow[b]{2}{*}{$\mathrm{t}$} & \multirow[b]{2}{*}{ Sig. } \\
\hline & $B$ & $\begin{array}{l}\text { Std. } \\
\text { Error }\end{array}$ & & & \\
\hline 1 (Constant) & 1,340 & 1,569 & & 2,854 & ,003 \\
\hline $\begin{array}{l}\text { Kualitas } \\
\text { produk }\end{array}$ & ,275 & ,084 & 316 & 3,274 & ,000 \\
\hline $\begin{array}{l}\text { Citra } \\
\text { merek }\end{array}$ & ,721 &, 117 & ,594 & 6,154 &, 000 \\
\hline
\end{tabular}

a. Dependent Variable: Keputusan pembelian

Sumber : Output SPSS yang diolah (2019)

Pengaruh dari masing-masing variabel X1 (Kualitas Produk) dan X2 (Citra Merek) terhadap $Y$ (keputusan pembelian) dapat dilihat dari arah tanda dan tingkat signifikan (probabilitas) dimana semua variabel mempunyai arah yang positif dan berpengaruh signifikan karena nilai signifikan $<0,05$ atau $5 \%$, atau pada t tabel dengan nilai signifikan 0,05 maka diperoleh t tabel 1,984 atau TINV $(0,05 ; 97)$.

a. Pengaruh Kualitas Produk (X1) terhadap keputusan pembelian (Y)

Hasil uji parsial (uji t) antara Kualitas Produk terhadap keputusan pembelian menunjukan nilai $t$ hitung $>\mathrm{t}$ tabel $(3.274<1,984)$ dan sig $<0,05(0,000<0,05)$ sehingga Ho ditolak dan Ha diterima yaitu "terdapat pengaruh Kualitas Produk terhadap keputusan pembelian" Kosmetik Wardah PT. Paragon Technology and Innovation.

b. Pengaruh Citra Merek (X2) terhadap keputusan pembelian (Y)

Hasil uji parsial (uji t) antara pelayanan terhadap keputusan pembelian menunjukan nilai $t$ hitung $<\mathrm{t}$ tabel $(6.154<1,984)$ dan sig<0,05 $(0,000<0,05)$ sehingga Ho ditolak dan Ha diterima yaitu "terdapat pengaruh Citra Merek terhadap keputusan pembelian" pada Kosmetik Wardah PT. Paragon Technology and Innovation.

\section{Hasil Uji Simultan (Uji F)}


Tabel 4.26

Uji F (Simultan)

ANOVA $^{\mathrm{a}}$

\begin{tabular}{|c|c|c|c|c|c|}
\hline \multicolumn{1}{|c|}{ Model } & $\begin{array}{c}\text { Sum of } \\
\text { Squares }\end{array}$ & Df & Square & F & Sig. \\
\hline 1 Regression & 4468,807 & 2 & 2234,403 & 170,897 & $.000^{\mathrm{b}}$ \\
Residual & 1268,233 & 97 & 13,075 & & \\
Total & 5737,040 & 99 & & & \\
\hline
\end{tabular}

a. Dependent Variable: Keputusan pembelian

b. Predictors: (Constant), Citra merek, Kualitas produk

Bedasarkan gambar tabel f diatas, dengan nilai df (n1) 2, df (n2) 97, dan taraf signifikansi 5\% atau 0.05 maka didapatkan nilai $f$ tabel adalah sebesar 3.09 (lihat pada lampiran $f$ tabel).

Dari hasil uji $F$ dapat diperoleh nilai $f$ hitung $>f$ tabel yaitu $170.897>3,09$ dan nilai sig $<0,05$ atau 0,000 0,05 terdapat pengaruh Kualitas Produk dan Citra Merek secara simultan terhadap keputusan pembelian Kosmetik Wardah pada PT. Paragon Technology and Innovation.

\section{KESIMPULAN DAN SARAN}

\section{Kesimpulan}

Berdasarkan hasil penelitian uji regresi berganda, menunjukkan bahwa kualitas produk dan citra merek berpengaruh positif terhadap keputusan pembelian dengan persamaan regresi $Y=1.340+0,275 X 1+0,721 X 2$, dengan koefisiensi korelasinya sebesar 0,883, berada pada interval 0,80-0,1000 dengan korelasi sangat kuat. Dengan koefisien determinasi ( $R$ square) sebesar $77.9 \%$ hasil uji $F$ dapat diperoleh nilai $f$ hitung $>\mathrm{f}$ tabel yaitu $170.897>3,09$ dan nilai sig $<0,05$ atau 0,000 $<0,05$ terdapat pengaruh Kualitas Produk dan Citra Merek secara simultan terhadap keputusan pembelian pada kosmetik Wardah. 


\section{Saran}

Perusahaan harus selektif dalam penentuan Kualitas Produk dan meningkatkan kembali Citra Merek, serta meningkatkan promosi, dengan berbagai iklan yang lebih menarik.

\section{G. DAFTAR PUSTAKA}

Abdul Choliq, "Pengantar Manajemen", Gramedia, Jakarta, 2014.

Akbar

Ajija, Shochrul R,"Cara Cerdas Menguasai EViews", Salemba Empat, Jakarta, 2011.

Ali, Hasan,"Marketing dan Kasus-Kasus Pilihan", CAPS (Center For Academic Publishing Service), Yogyakarta, 2013.

Alma, Buchari,"Manajemen Pemasaran dan Pemasaran Jasa", CV Alfabeta, Bandung, 2012.

Alma, Buchari,"Manajemen Pemasaran dan Pemasaran Jasa", CV Alfabeta, Bandung, 2013.

Anton Mulyono Aziz dan Maya Irjayanti ,"Manajemen”, Gramedia, Bandung, 2014.

Arikunto, Suharsimi,"Prosedur Penelitian Suatu Pendekatan Praktek", Rineka Cipta, Jakarta, 2012.

Bambang Prasetyo dan Lina Miftahul Jannah,"Metode Penelitian Kuantitatif : Teori dan Aplikasi”, PT Rajagrafindo Persada, Jakarta, 2012.

Danang, Sunyoto,"Metodologi Penelitian Akuntansi", PT Refika Aditama Anggota Ikapi, Bandung, 2013.

Danang Sunyoto "Teori Kuesioner dan Analisi Data untuk Pemasaran dan Perilaku Konsumen", Graha IImu, Yogyakarta, 2013.

Daryanto,"Manajemen Pemasaran: Sari Kuliah", Satu Nusa, Bandung, 2011.

E. Sikula, Andrew,"Manajemen Sumber Daya Manusia", Erlangga, Bandung, 2011.

Feriyanto, Andri dan Shyta, Endan Triana," Pengantar Manajemen (3 in 1)", Alfabeta, Bandung, 2010.

Hanafie, Rita,"Pengantar Ekonomi Pertanian", ANDI, Yogyakarta, 2010.

Ghozali, Imam,"Aplikasi Analisis Multivariate dengan Program IBM SPSS 21", Edisi 7, Universitas Diponegoro, Semarang, 2013.

Ghozali, Imam,"Aplikasi Analisis Multivariete Dengan Program IBM SPSS 23", Edisi 8 Cetakan ke VIII, Badan Penerbit Universitas Diponegoro, 2016.

Hanafie, Rita,"Pengantar Ekonomi Pertanian", ANDI, Yogyakarta, 2010.

Hasibuan,“Manajemen : Dasar, Pengertian, dan Masalah”, Edisi Revisi, , PT Bumi Aksara, Jakarta, 2017. Keller, Kevin Lane,"Strategic Brand Management Building Measuring and Managing Brand Equity", 4th edition, Pearson Education, USA, 2013. 
Keller, Kevin L,"Strategic Brand Management ; Building, Measuring, and Managing Brand Equity', Fourth Edition Harlow, Pearson Education Inc, English; 2013.

Kotler, P dan Keller, K,"Marketing Management", 14th Edition, Pearson, United States of America, 2012.

Kotler, P dan Keller, K,"Manajemen Pemasaran", Edisi 12, Jilid 1. Terjemahan oleh Benyamin Molan, PT. Indeks, Jakarta, 2010.

Kotler, P dan Keller, K,” Manajemen pemasaran “, Edisi 12, Erlangga, Jakarta, 2012.

Kotler, Philip, dan Amstrong,"Prinsip-prinsip Pemasaran", Edisi 13 Jilid 1, Erlangga, Jakarta, 2012

Kotler, Philip. \& Gary Armstrong," Principle Of Marketing", Pearson Prentice Hall, New Jersey 2014.

Kotler, Philip and Keller, Kevin Lane,"Manajemen Pemasaran”, Jilid 1, Edisi 13, Erlangga, Jakarta, 2013.

Kotler, Philip and Keller, Kevin Lane,"Manajemen Pemasaran”, Jilid 2, Edisi 13, Erlangga, Jakarta, 2013.

Lupiyoadi, Rambat,"Manajemen Pemasaran Jasa Teori dan Praktik", Salemba Empat, Jakarta, 2014.

Rangkuti, Freddy," Analisis SWOT", PT Gramedia Pustaka Utama, Jakarta, 2015.

Rangkuti, Freddy," Customer Care Excellence", Gramedia, Jakarta, 2017.

Sudaryono, "Manajemen Pemasaran: Teori dan Implementasi", Andi, Banten, 2016.

Sugiyono,"Metode Penelitian Pendidikan Pendekatan Kuantitatif, kualitatif, dan R\&D", CV Alfabeta, Bandung, 2010.

Sugiyono,"Metode Penelitian Kuantitatif, Kualitatif dan R \& D", CV Alfabeta, Bandung, 2011.

Sugiyono, "Metode Penelitian Kuantitatif, Kualitatif dan R\&D", CV Alfabeta, Bandung, 2012.

Sugiyono, "Metode Penelitian Kuantitatif, Kualitatif, dan R\&D", CV Alfabeta, Bandung, 2016

Sugiyono, "Metode Penelitian Kuantitatif, Kualitatif, dan R\&D”, CV Alfabeta, Bandung, 2017

Supardi," Aplikasi Statistika dalam Penelitian Konsep Statistika yang Lebih Komprehensif, Change Publication, Jakarta, 2013.

Tjiptono, Fandy,"Strategi Pemasaran”, Edisi 2, Andi, Yogyakarta , 2014.

Tjiptono, Fandy,"Strategi Pemasaran”, Edisi 4,Andi, Yogyakarta, 2015 